\title{
Circulação e construção de circuitos: a dinâmica do rádio
}

Viviane Borelli

Universidade Federal de Santa Maria, Santa Maria, Rio Grande do Sul, Brasil

Maicon Elias Kroth

Universidade Federal de Santa Maria, Santa Maria, Rio Grande do Sul, Brasil

\section{Resumo}

Analisa-se o modo como se estruturam fluxos comunicacionais dinamizados pela ação dos sujeitos participantes da sociedade em midiatização e que são capturados pelo programa Timeline, da rádio Gaúcha, de Porto Alegre, RS. A partir da realização de entrevistas, audições e observação de perfis de jornalistas e do programa no Facebook, descreve-se circuitos interacionais, detalha-se o funcionamento e mostra-se a reconfiguração do dispositivo radiofônico. A análise dos fluxos comunicacionais denota a constituição de uma arquitetura de circuitos complexos nos quais a circulação emerge e reestrutura práticas não só do rádio, mas também da própria sociedade em midiatização.

Palavras-chave

Circulação. Circuitos. Rádio. Midiatização.

\section{Introdução}

O artigo problematiza a estruturação de uma arquitetura complexa de fluxos comunicacionais que possibilitam a circulação discursiva a partir da constituição de circuitos de interação midiáticos e não midiáticos (BRAGA, 2017). Nessas dinâmicas complexas, estes últimos podem se interpolar aos primeiros e vice-versa, pois a circulação discursiva evidencia fluxos em múltiplas direções.

Entende-se que a complexidade da constituição do dispositivo radiofônico resulta de lógicas de uma sociedade compreendida, nos termos dessa pesquisa, como em processo de midiatização (VERón, 1997, 2004, 2013). Adota-se a perspectiva de que o processo de midiatização está em curso e inacabado, ou seja, de que a sociedade está em midiatização. Não se trata, portanto, de uma sociedade midiatizada, termo que remeteria a um fenômeno acabado e findo. 
Diante disso, é necessário evidenciar que a investigação se faz a partir do entendimento de tal ambiência formada por processualidades constantemente construídas e desconstruídas pelos sujeitos participantes ${ }^{1}$. Concorda-se com Gomes (2017, p. 134), quando ele defende que "[...] a realidade da sociedade em midiatização supera e engloba as dinâmicas particulares que esta engendra para se comunicar". Segundo o autor, vivemos numa ambiência em que há um novo modo de ser no mundo provocado por processos que decorrem não só do desenvolvimento tecnológico, mas, sobretudo, de sociabilidades em constante construção.

Nesse contexto, a sociedade em permanente mutação, nos desafia como pesquisadores do campo da Comunicação, a desenvolver estratégias de pesquisa que busquem ir além do produto, pois cada vez mais a recepção produz marcas discursivas que possibilitam a observação de fluxos comunicacionais entre os participantes. Se outrora, segundo perspectivas funcionalistas, era possível compreender o processo de comunicação como um fluxo direto, de mão única entre um emissor e um receptor, com a complexificação da sociedade, em que emerge a problemática da circulação, é preciso avançar.

Pesquisadores como Jésus Martín-Barbero que há mais de 30 anos chamava a nossa atenção para as mediações, em que era necessário retirar o foco dos meios para poder mostrar as complexidades entre cultura, comunicação e tecnicidade -, e Eliseo Verón - que problematizava em suas obras a necessidade de extrapolar a produção para ir até o reconhecimento, apontando as complexidades constitutivas da semiose social.

Fausto Neto (2018, p. 89) reflete sobre as perspectivas construídas pelos dois autores no contexto das pesquisas latino-americanas, indicando especificidades e pontos de convergências entre os conceitos de mediação e midiatização. Para o autor, o trajeto que Martín-Barbero faz das medições às interfaces, “[...] enseja hibridações de vários níveis que vão além da especificidade de cada meio, o que vai ensejar o surgimento de uma nova ecologia comunicacional". De outro lado, em sua trajetória de pesquisa, Verón sempre destacou a heterogeneidade constitutiva entre produção e reconhecimento, mostrando as complexidades que perpassam as relações 
entre as mídias e os atores sociais e as dinâmicas interacionais que são construídas. Verón (1997) destaca as afetações múltiplas entre instituições, atores sociais e mídias para além de uma proposição funcionalista de que a mídia é usada para algum fim, ou seja, a mídia transforma o modo através do qual nossas relações são construídas, portanto, novas semioses e sociabilidades emergem dessa processualidade. Dessa forma, compreender a circulação discursiva torna-se uma questão desafiadora para os estudos em comunicação.

Fundamentados em perspectivas teóricas que vão além do produto midiático, nesta pesquisa, a circulação é entendida não mais como um ponto de passagem (FAUSTO NETO, 2010), mas como um ambiente complexo que nos possibilita compreender - por meio de marcas discursivas muito específicas como ocorrem as trocas comunicacionais na sociedade em vias de midiatização. Ao estudar esses fluxos interacionais, amplia-se o olhar não só para contextos específicos, pois por meio desse tipo de estudo é possível fazer inferências sobre processualidades comunicacionais emergentes e em constantes mutações.
Para mostrar o funcionamento das dinâmicas de circulação, analisa-se o modo como se estruturam circuitos interacionais a partir da observação da complexidade constitutiva do Timeline, programa radiofônico que vai ao ar, de segunda a sexta, das $10 \mathrm{~h}$ às $11 \mathrm{~h}$, pela rádio gaúcha, de Porto Alegre, Rs e pelo Portal Gauchazh. Os temas são os mais diversos, desde política, economia até entretenimento, em formato de talk show, no qual os apresentadores - Kelly Matos, Luciano Potter e David Coimbra - enunciam notícias, fazem comentários e emitem opiniões. Segundo a descrição do site GauchazH, os apresentadores “[...] trazem as principais informações do dia sobre comportamento, cultura, humor, futebol, cotidiano, política e opinião"2.

Assim, 0 interesse pelo programa radiofônico se dá em meio a uma mutação do meio de comunicação a partir do que Prata (2008) chamou de radiomorfose. A mutação ocorrida no rádio nos anos 90 do século passado se intensificou com a chegada da internet, permitindo possibilidades de reinvenção de uma de suas principais características, a interatividade, como apontam Almeida e Magnoni (2009). Para os autores, "0 rádio sempre foi o meio mais interativo por possibilitar o acesso dos ouvintes à emissora, por telefone ou carta. Com a internet, essa interatividade aumenta consideravelmente" (p. 4). 
No Timeline, o acesso a recursos tecnológicos midiáticos como as redes sociais digitais e o aplicativo de conversação WhatsApp possibilitou que o mesmo se tornasse ainda mais interativo, reconfigurando a sua forma de apresentação aos seus ouvintes-internautas. Dessa forma, tanto jornalistas produtores da informação radiofônica quanto os participantes dos circuitos comunicacionais, constituem fluxos e dinâmicas discursivas do programa.

A partir do momento em que foi possível consumir conteúdos radiofônicos através da internet, o grupo RBS, a quem pertence a Rádio Gaúcha, tratou de reforçar a construção de circuitos interacionais organizados a partir da arquitetura do website de GaúchazH, fazendo emergir o protagonismo das redes sociais digitais. Os jornalistas responsáveis pelo Timeline captam e equacionam, de forma ininterrupta, questões que circulam nas ambiências sociais digitais, trazendo temas para dentro do programa. O debate se faz a partir de aprofundamento e interpretação jornalística.

Tais transformações do meio radiofônico se refletiram em mudanças nas rotinas produtivas, percebidas principalmente pela incorporação das tecnologias no cotidiano de produção dos radiojornalistas do Timeline. Nessas condições, os profissionais precisaram acompanhar a evolução do próprio ouvinte-internauta, o qual, a partir de lógicas de coprodução, se vê cada vez mais conectado com a emissora e com o programa. O programa, nesse sentido, se estruturou conforme lógicas multimidiáticas, organizadas em torno da ambiência digital, com características as quais se configuram naquilo que Lopez (2009) chama de rádio hipermidiático, ou seja, "que fala em diversas linguagens, em distintos suportes e, ainda assim, mantém no áudio seu foco" (p. 119).

A disputa pelos públicos obriga os empresários do setor a repensar seus modelos de produção, fazendo investimentos que se estruturam não apenas em torno de fluxos produtivos, mas cada vez mais atentos a lógicas de consumo. Investigações de Ferraretto, desde 2010, já apontam os caminhos do rádio contemporâneo. Para o pesquisador, dentre algumas características que se podem delinear na oferta de conteúdos radiofônicos, o que não implicaria, necessariamente, uma predominância, é possível apontar:

a) a passagem de uma lógica da oferta a uma lógica da demanda; b) a possibilidade de optar entre a comunicação ponto-massa e a pontoponto associada ou não à flexibilização do consumo pela personalização do conteúdo e do momento de sua recepção; c) uma maior interatividade, mesmo que simbólica, entre o emissor e o receptor, mediada pela tecnologia. (FERRARETTO, 2010 , p. 552). 
As percepções do investigador vão ao encontro do que Del Bianco (2010) entende ao afirmar que a comunicação radiofônica, apesar de ser predominantemente sonora, incorpora outros elementos. "O novo rádio proporciona mudanças na linguagem radiofônica, no formato de programação e na construção de novas formas de interação com a audiência, já que se trata de um ambiente multimídia de base interativa" (p. 91).

A mesma percepção é apontada pelos estudos de Kischinhewsky (2016), que caracteriza o rádio como expandido, oferecendo novos serviços e canais de distribuição. O rádio se espalha para as mídias sociais digitais, que potencializam o alcance e a difusão de seus conteúdos. Para ele, são "[...] serviços que se alimentam de conteúdos gerados pelos usuários, possibilitam a comunicação interpessoal e a multicomunicação [...]" e outros atributos os quais são considerados "decisivos no reposicionamento da radiofonia no ambiente midiático" (p.39).

A produção de conteúdo para o rádio não se restringe mais apenas aos elementos sonoros, mas contempla também o que ele define como "elementos parassonoros, ou seja, fotos, vídeos, ícones, infográficos e outras ilustrações de sites de emissoras" (p.32). O rádio, hoje,
[...] extrapola as transmissões em ondas hertzianas e transborda para as mídias sociais, o celular, a TV por assinatura, sites de jornais, portais de música. A escuta se dá em frequência modulada (FM), ondas médias (AM), curtas e tropicais, mas também em telefones celulares, tocadores multimídia, computadores, notebooks, tablets; pode ocorrer ao vivo (no dial ou via streaming) ou sob demanda (podcasting ou através da busca em arquivos ou diretórios) (p. 13-14).

Nessa perspectiva, mais recentemente, ao investigar os modelos de negócio e o poder de referência do meio, Ferraretto (2019) afirma que o rádio vai disputar o seu protagonismo no campo do áudio. Ainda, para ele, as transformações no rádio estão aceleradas, e que o mesmo tenderia a ganhar outros concorrentes em áudio. Ferraretto (2019, p. 161) compreende que "Aparentemente, o principal conteúdo a desafiar as estações constituídas é também uma manifestação considerada, pela linguagem e pelos formatos, como radiofônica, mas que não tem sido explorada no limite de suas possibilidades pelas próprias emissoras: o podcast."

\section{Desafios do percurso metodológico diante da emergência da circulação}

Ao observar o dispositivo radiofônico e problematizar as relações entre produção e reconhecimento num contexto de transformações das práticas sociais em função do processo de midiatização da sociedade (marcas de autoria), 
com base especialmente em Verón (2004, 2013), e apontar a emergência da circulação, estabelece-se a necessidade de desenvolver uma série de procedimentos metodológicos para dar conta dessas complexidades.

A escuta foi um primeiro movimento necessário para a identificação de marcas discursivas que apontaram para mutações no radiojornalismo. Dessa maneira, foi por meio de audições de distintos programas radiofônicos em várias emissoras que se identificou transformações nos modos de produção radiofônica e no programa Timeline. A pesquisa foi desenvolvida a partir da ideia de que a comunicação pode se configurar numa disciplina indiciária, como Braga (2008, p. 6) problematiza através das perspectivas de Ginzburg (1989) e de Sebeok e Umiker-Sebeok (2004) e defende que não basta colher indícios, pois é preciso "selecionar e organizar para fazer inferências".

Ginzburg (1989, p. 154) cita distintos modos de produção de conhecimento ao longo da história da humanidade e que tomam como base o paradigma indiciário, como a semiótica médica que é diagnóstica e prognóstica, formas de saber na antiga Mesopotâmia que apontam para atitudes orientadas à "análise de casos individuais, reconstruíveis somente através de pistas, sintomas, indícios". O autor compreende que o paradigma indiciário ou semiótico "penetrou nos mais variados âmbitos cognoscitivos, modelando profundamente as ciências humanas. Minúsculas particularidades paleográficas foram empregadas como pistas que permitiam reconstruir trocas e transformações culturais" (p. 177). Assim, ao seguir pistas, observar pormenores e detalhes é que se pode gerar conhecimento, refletir e inferir sobre as transformações nos fluxos comunicacionais em permanente circulação.

Nesse contexto, compreendeu-se que era necessário, inicialmente, ouvir para poder identificar indícios capazes de nortear os próximos passos da investigação e possibilitar a inferência sobre os observáveis. Dessa maneira, o desenho metodológico envolveu uma série de ações abaixo detalhadas - e que foram construídas enquanto estratégias teórico-metodológicas que visaram produzir um diálogo permanente entre conceitos e ferramentas técnicas necessárias para estudar o objeto.

Nesse contexto, para investigar a complexidade da construção desses circuitos e descrever os distintos fluxos comunicacionais, inicialmente, foram feitas audições sistemáticas no mês de agosto de 2018 , por meio de escuta dos programas disponibilizados 
no portal Gaúcha $Z H^{3}$. A partir da escuta de 10 programas veiculados no mês de agosto, foi possível apontar marcas discursivas que deram subsídios para organizar um protocolo de pesquisa que visasse a observação dos modos de operação do programa e a organização de perguntas com o intuito de ouvir posteriormente produtores e apresentadores.

Foi por meio das audições, portanto, que se identificou alguns fluxos comunicacionais em construção. Na sequência, a fim de buscar compreender como ocorre a construção dos circuitos e como estes são dinamizados pelo programa radiofônico, avançou-se na pesquisa por meio da realização de entrevistas presenciais com os jornalistas - tanto apresentadores quanto produtores do programa. A partir de um roteiro de questões, organizado em formato de perguntas abertas, as entrevistas - caracterizadas como semiestruturadas (GIL, 2008) -, foram feitas no dia 31 de agosto de 2018, na sede da rádio Gaúcha, em Porto Alegre, Rs. Dentre as questões formuladas, estavam temas relativos a modos de apuração, interação com os públicos, distintas linguagens e formatos, além da distribuição dos conteúdos em circulação. Também foi realizada uma observação in loco, na qual foi possível perceber e revelar as operações desencadeadas pelos participantes responsáveis pela produção do Timeline em termos de rotinas produtivas radiofônicas.

A observação in loco possibilitou o levantamento de indícios que não haviam sido identificados até então. Diante da constatação de rotinas produtivas não perceptíveis por meio da escuta apenas, como, por exemplo, algumas marcas de convergência midiática (LOPEZ, 2010), se entendeu ser necessário continuar as audições, o que foi feito durante o mês de setembro de 2018. A partir dessas escutas posteriores às entrevistas semiestruturadas e da observação nos estúdios da emissora coletou-se enunciados de sujeitos participantes que postaram comentários nos perfis do programa radiofônico na rede social Facebook.

Compreende-se que a reconfiguração do dispositivo radiofônico num contexto de cultura da convergência (JENkINS, 2008) e de midiatização da sociedade pode também ser vislumbrada por meio de uma observação de comentários - locus no qual os participantes podem expressar suas opiniões sobre o programa. Assim, como última etapa da pesquisa, elegeu-se para análise de marcas 
discursivas (VERÓN, 2004, 2013) comentários que expressassem mudanças assinaladas em estudos sobre radiojornalismo hipermidiático, como, por exemplo, a perspectiva de Lopez (2010) que aponta para uma complexificação da narrativa radiofônica.

Nessa perspectiva de olhar o objeto a partir de sua complexidade constituinte, avalia-se que os caminhos metodológicos não deveriam focar em apenas uma das instâncias, como da produção. Assim, avaliou-se a necessidade de avançar em termos de observação do objeto indo além do produto e das gramáticas de produção (VERón, 2004, 2013). Concorda-se com o autor quando afirma que as marcas produzidas pela circulação apontam para a necessidade de entender as relações complexas entre produção e reconhecimento, salientando que as instâncias não podem ser compreendidas de forma separada, já que cabe aos participantes dos episódios comunicacionais realizar fluxos adiante de variadas formas (BRAGA, 2017).

Fausto Neto (2010, p. 55) já postulava que a circulação "[...] institui novas formas de interações entre produtores e receptores de mensagens, complexificando seus papéis, ao organizá-los segundo novas dinâmicas de interfaces". As dinâmicas propostas pelo dispositivo interacional, por sua vez, podem ser compreendidas através das articulações - das operações que ocorrem dentro do dispositivo e fora, as quais não repercutem apenas no seu interior, mas que fazem transitar incessantemente informações por meio de processos reiterados e em múltiplas direções.

O termo dispositivo pode ser apreendido em diferentes sentidos, mas neste trabalho, adota-se o conceito desenvolvido por Braga (2017). Para o pesquisador, dispositivos interacionais são matrizes elaboradas e reelaboradas socialmente com o objetivo de produzir e acionar interações. $\mathrm{O}$ autor ressalta que o elemento tecnológico, por mais solidificado que seja, não deve ser considerado como dispositivo interacional, pois se constitui num "[...] conjunto heterogêneo de materiais e de processos que não decorrem necessariamente da tecnologia, e que, sobretudo, podem dar direção e sentido a seu uso" (BRAGA, 2017, p. 37). O dispositivo interacional é compreendido, portanto, como um ambiente formado por fluxos difusos, em que é possível identificar alguns momentos singulares dessas processualidades comunicacionais.

Assim, no caso estudado, o que se observa não é apenas o programa Timeline em si ou o perfil em redes sociais, nem mesmo o portal de Gaúchazh, mas distintos elementos que constituem sua complexidade, como as trocas comunicacionais entre os participantes em momentos específicos dos fluxos que 
acabam codeterminando e reestruturando o programa ao vivo, além de alguns fluxos anteriores e que prosseguem adiante. Como referido, compreende-se que para apreender o processo de circulação é preciso olhar mais do que o produto em si, pois o dispositivo não é um mero aparato técnico, mas um conjunto tecno-simbólico, formado por elementos técnicos e sócio-discursivos.

Neste sentido, o dispositivo radiofônico observado em operação constitui um contexto singular de produção de processos interacionais por meio de suas particularidades articuladas já que se observam ações que remetem a características do rádio hipermidiático (LOPEZ, 2010). A diferença com relação ao meio no qual ele está inserido se expressa pelo estabelecimento de suas atividades, a partir de seus próprios limites, mediante operações exclusivas, na qual a comunicação ali produzida desenvolve lógicas próprias de conexão, com regras que pretendem otimizar a capacidade de dinamizar circuitos de comunicação e fluxos adiante (BRAGA, 2012, 2017).

A partir da constatação de que o Timeline é um programa produzido a partir de lógicas da convergência midiática, toma-se como norteadores os conceitos de dispositivo interacional e de circuito formulados por Braga (2017) para explicar fluxos comunicacionais contínuos em contextos específicos. Para o autor, “[...] a cada ponto nodal ou "estação" identificável, são realizadas ações interacionais, adjunção de códigos, geração de inferências - desenvolvendo portanto outros sistemas de relações entre os componentes aí articulados" (p. 45). Nesse cenário, serão identificados pontos nodais, analisados fluxos comunicacionais e detalhado o funcionamento de circuitos construídos por distintos sujeitos em um contexto singular de reconfiguração do dispositivo radiofônico.

\section{Circulação e construção de circuitos}

Compreende-se que o cenário que abrange processos crescentes de uma sociedade em vias de midiatização obriga o rádio a repensar os modos de como constituir circuitos interativos capazes de potencializar vínculos com a recepção. Com o volume cada vez maior de discursos que circulam e são produzidos tanto pela instância de produção quanto da recepção, o rádio foi se reestruturando sistematicamente.

Segundo García Avilés, Salaverría e Masip (2008), o desencadeamento da convergência das redações se tornou necessário a partir de um novo formato de gestão dos processos de produção de conteúdo. Essa reestruturação produziu, no rádio, a aceleração dos fluxos de produção e disponibilização de conteúdos e a propagação de plataformas para distribuir as notícias. Do mesmo modo, alterou as práticas 
de coleta e edição das mesmas e, ainda, de relacionamento com as fontes. Nesse sentido, serviços de radiofonia se estruturam em torno da constituição de espaços de fruição e interação entre diversos atores envolvidos em múltiplos circuitos comunicacionais. Estes espaços, por sua vez, são capazes de estimular não só a participação dos rádio-internautas, mas a distribuição de conteúdo radiofônico. As redes sociais digitais e os sistemas de mensagem instantânea gratuitos, como o WhatsApp, são cada vez mais utilizadas em operações de apuração, produção de textos e distribuição de conteúdo produzido em emissoras radiofônicas.

Nessas condições, o uso da internet passou a se constituir parte do próprio processo de checagem de informação em emissoras de radiojornalismo. As tarefas de escolher, entre dezenas de acontecimentos, apenas os que são considerados notícia, fragilizou o processo de conferência, causando deficiências no trabalho investigativo. É preciso mencionar que junto com os avanços tecnológicos também vieram os enxugamentos de equipe de profissionais responsáveis pela produção de informações. Em consequência, há um processo de acúmulo de habilidades técnicas necessárias para lidar com lógicas de produção a cada instante renovadas. Configura-se, com este processo, a exigência por um jornalista que desenvolva múltiplas funções e que seja capaz de compreender o novo ambiente em que o rádio se insere e a necessidade que ele tem de se apresentar como multiplataforma e como um dispositivo cada vez mais interativo.

Historicamente, o rádio se consolidou a partir da premissa da proximidade, da participação ao vivo e em tempo real. O meio de comunicação se configurou com um os principais dispositivos de aproximação entre lógicas de produção e recepção midiática, a partir de suas estruturas de interação continuamente reinventadas. Contemporaneamente, as possibilidades de contato oferecidas pelas emissoras de rádio se multiplicaram ainda mais, especialmente por meio do desenvolvimento de tecnologias e processos. Novas plataformas, como as redes sociais digitais, se estabeleceram como uma das principais formas de estímulo à conversação entre os sujeitos envolvidos em "[...] processos mais ou menos reiterados de conexão e de tensionamento entre diferentes tipos de episódios" (BRAGA, 2017, p. 44).

Ao observar a sobrevivência do rádio e seu desenvolvimento até os dias atuais, Fernández (2009) afirma a sua inegável competência de articulador de operações tecnodiscursivas. O rádio participa da vida do cidadão, estimula o mesmo a midiatizar a complexidade social. Essa competência lhe confere uma capacidade 
de engendrar vínculos com a sua audiência, ou seja, o rádio, por meio do uso das novas tecnologias à disposição, reorganiza sistematicamente suas lógicas de conexão, apostando na constituição do que se nomeia como uma arquitetura criativa de interatividade.

O dispositivo radiofônico é um organismo vivo, complexificado pelo processo de midiatização, o que permite diversas interpretações, que partem do pressuposto de que a sociedade se constitui por meio da comunicação. Para Gomes (2017, p. 126), "o conteúdo da comunicação é a expressão da vida dessa sociedade: passado, presente, futuro, história, sonhos, etc. O resultado é o compartilhamento de vivências entre as pessoas e todas as gerações". Para o autor, a midiatização é uma chave hermenêutica para compreensão e interpretação da sociedade ao considerar que "a midiatização se organiza em torno ao consumo relacionado com as produções de sentido social" (p. 94).

Trata-se de um processo o qual se desenvolve acerca da construção de circuitos capazes de colocar em circulação os discursos por meio de estratégias midiáticas, resultando em processualidades mais complexas que relações antes pontuais e lineares, por exemplo, entre emissor e receptor. Este cenário de desenvolvimento constante de lógicas articuladoras entre participantes e processos comunicacionais, se constrói em torno de fórmulas de participação organizadas em arquiteturas dinâmicas cada vez mais complexas de circulação (FAUSTo NETo, 2010, 2016). Assim, torna-se relevante observar essas processualidades por meio da descrição e análise da constituição de múltiplas relações que se estabilizam e se desestabilizam conforme a própria dinâmica da vida.

Fausto Neto $(2010,2016)$ defende que há uma transformação profunda na sociedade, não mais centralizada nos meios, mas em processualidades que redesenham as relações dos sujeitos com os fenômenos midiáticos. O autor problematiza que essa complexificação aponta para a existência de ações comunicativas cada vez mais atravessadas por dinâmicas de interpenetrações. Esse que se afasta da noção funcionalista de uma "zona automática", antes concebida como intermediária e um lugar meramente de passagem entre produção e recepção.

Como consequência da complexificação gerada a partir da midiatização e de sua afetação em diversos âmbitos do cotidiano, o dispositivo radiofônico engendra relações por meio de tecnologias e discursos com outros dispositivos de interação para facilitar o acesso à informação e propiciar, sobretudo, maior participação do público na programação diária. Por meio da disponibilização de 
diferentes modalidades para contato, o rádio organiza uma estrutura relacional, possibilitando que os participantes manifestem seus sentidos sobre as demandas discursivas postas em circulação. É preciso lembrar que a sociedade também se organiza em torno das mídias e de seus modos de operação, em relações mais ou menos reiteradas e em permanente construção.

No entanto, embora a midiatização da sociedade tenha trazido uma intencionalidade operacional aos circuitos de comunicação, Braga (2017) entende que estes não se restringem nem aos produtos que circulam, nem aos momentos diretamente midiáticos. Para o autor,

Nos macro-ambientes de interação social, do qual fazem parte, aliás, as redes sociais - e na medida em que as interfaces sociais se encadeiam crescentemente, percebemos que o esforço interacional se desloca do modelo conversacional (comunicação reverberante, de ida-e-volta) para um processo de fluxo contínuo, sempre adiante. (BRAGA, 2012, p. 40).

Os circuitos contínuos construídos pelas relações entre o rádio e seus participantes, fazem com que a circulação permaneça acontecendo em vários ambientes, sejam midiáticos ou não midiáticos. Braga (2012, p. 39) entende que "os produtos circulantes da "mídia de massa" são retomados em ambientes que ultrapassam a situação de recepção" e que é relevante compreender como o receptor faz seguir adiante interpretações próprias a partir do que consome. Nesse sentido, os circuitos comunicativos podem ser entendidos como teias de relações que se constituem por meio de ofertas discursivas, sejam produzidas pelos participantes ou pelo dispositivo radiofônico.

Dentro desta perspectiva, o produto ou mensagem não é só o que circula, já que há um sistema de circulação no qual se viabilizam distintas produções de sentidos. BRAGA (2017) faz essa ressalva: o produto é um momento particular da circulação, pois já está consolidado em sua forma que permanece (e que se multiplica, na sociedade em midiatização), continuando a circular e repercutir em outros espaços. Para o autor, o produto, por sua permanência e também porque se molda ao mesmo tempo em que busca moldar os ambientes em que se põe a circular, pode tornar-se um especial objeto de observação para inferências sobre os processos mais gerais em que se inscreve.

\section{A dinâmica dos circuitos comunicacionais}

Entende-se que o programa radiofônico Timeline se constitui num caso peculiar a partir do modo como se estrutura, iniciando pelo nome que se refere às timelines - linhas do tempo - de páginas de perfis 
de redes sociais digitais. Para a jornalista Kelly Mattos, "o programa foi criado para acompanhar a timeline. A gente quer saber o que as pessoas estão talkando, o que estão falando, esse é o propósito do programa. O critério é esse: estar falando. O que circula nas redes"4 (grifo nosso). Os jornalistas produtores e apresentadores do programa o definem como um talk show, enfatizando que a principal característica é a conversação, com doses de humor.

Trata-se, portanto, de um programa de variedades, que reúne informação e entretenimento por meio da identificação de elementos retirados do que se pode caracterizar como uma economia discursiva em rede. Os produtores e apresentadores identificam marcas discursivas no processo de circulação de temas que estão entre os trending topics, no Twitter, nas timelines dos seus perfis no Facebook, no Stories do Instagram e nos grupos de WhatsApp para então avaliar o que pode ou não entrar no programa. A partir desses processos de captura de fragmentos discursivos da tessitura social (VERÓN, 2004, 2013), há ressignificações que visam dar continuidade aos fluxos e garantir a construção de novos circuitos.
O dispositivo radiofônico organiza-se em torno de uma arquitetura sistematizada de fluxos comunicacionais, pelos quais circulam discursos decorrentes de elaborações tentativas de comunicação, como assinala Braga (2017), em processos mais ou menos reiterados e que visam a articulação com outros dispositivos interacionais. Por se tratar de distintos fluxos interacionais, para melhor sistematizar os observáveis, descreve-se e analisa-se a dinâmica do circuito não a partir de uma lógica temporal, já que esses processos se interpõem em fluxos contínuos.

Aparentemente, o Timeline inicia no momento em que os apresentadores entram no ar, ao vivo, às 10 horas da manhã. Entretanto, como frisa Braga (2017), o produto midiático não é, necessariamente, o objeto inicial de um fluxo já que as dinâmicas de interação estão em trabalho permanente. No programa analisado, que se estrutura em dinâmicas constituintes de mutações, a produção é realizada em curso constante tendo como base um trabalho de curadoria sistematizada por meio de fluxos comunicacionais dinamizados por dispositivos interacionais, como o portal GaúchazH, o grupo de WhatsApp e as redes sociais digitais. 
O Timeline inscreve-se em distintos circuitos comunicacionais, entre os quais o portal GaúchazH, que centraliza informações das redações da rádio Gaúcha e do jornal Zero Hora, desde setembro de 2017. O portal pode estruturar vínculos por meio do sistema de notificação $p u s h^{5}$, no qual a informação vai ao encontro dos participantes do ambiente digital, que tem a possibilidade de escolher como, quando e onde vai consumi-la. Outra possibilidade de trocas e fluxos interacionais é por meio de um app para plataformas móveis, como aparelhos de telefone celular ou tablets. O app, apesar de ter uma estrutura de acessibilidade parecida com o portal GaúchazH, apresenta possibilidades de construção de circuitos interativos com os demais dispositivos que o programa integra. $\mathrm{O}$ app evidencia mais uma possibilidade dos participantes produzirem e difundirem conteúdos que circulam pelo sistema de relações organizado em torno do programa radiofônico.

A partir de um processo de curadoria sistematizado pelo software Chartbeat ${ }^{6}$, o portal
GaúchazH identifica o consumo dos conteúdos, detalha horário de acesso, tempo de permanência, número de participantes simultâneos, profundidade de acesso ao conteúdo e especificação de linhas lidas. Tais dados, capturados pela equipe de jornalistas do Timeline, são indicadores que auxiliam na estruturação da linha editorial do programa radiofônico. Como um protocolo de operação que faz parte da complexidade de um amplo circuito, a captação dos resultados da curadoria é uma das possibilidades avaliadas para conduzir o processo produtivo do Timeline, constituindo-se, assim, numa estação, num ponto nodal (BRAGA, 2017), pois possibilita interações e relações para fluxos comunicacionais que vão adiante.

Nessa complexidade observada, o dispositivo radiofônico é reconfigurado, pois depende de movimentos dos participantes que são identificados pelo software. Práticas e processos de apuração são executados a partir de fluxos diversos acionados pelos participantes das

5 "Push" é uma palavra que vem do inglês e significa "empurrar". Em tradução livre, portanto, as push notifications são notificações empurradas ao usuário. A tecnologia permite o envio de mensagens para smartphones e computadores conectados à internet sem que o destinatário as requisite. Ou seja, o próprio publicador inicia a transação e o conteúdo é "empurrado" mesmo sem solicitação. 0 aparelho de telefone celular emite um sinal, por meio de uma breve mensagem, quando um novo conteúdo está disponível para consumo. 0 mesmo ocorre nas telas de computadores.

6 Chartbeat é uma empresa de inteligência de conteúdo sediada na cidade de Nova York. Foi iniciada em 2009. Vende informações para editores, empresas de mídia e sites de notícias que eles podem usar para tomar decisões sobre o conteúdo para publicar e promover em seus sites. 
redes sociais digitais e não só pelos produtores. Se outrora, o dispositivo radiofônico centralizava a produção de informações, agora, há interpolações, ou seja, pode trabalhar diferentes circuitos que dão vida às processualidades em mutação.

Aplicativos como o WhatsApp e redes sociais digitais, como Facebook, Instagram e Twitter, são dispositivos interacionais que inscrevem-se em distintos circuitos - da produção à recepção e vice-versa para que a circulação aconteça. É de interesse do dispositivo radiofônico que eles funcionem, reiteradamente, como componentes que servem para manter, ampliar e dar forma aos circuitos interacionais colocados em marcha. Ou seja, acionar os dispositivos interacionais garante não só funcionamento de suas lógicas produtivas, mas também a manutenção do contato entre produtores e receptores, como assinalam Verón (2004, 2013), Fausto Neto $(2010,2016)$ e Braga (2012, 2017).

Nesse contexto, além do software curador, outro modo de sistematizar o processo de apuração é a constituição de um conjunto de fluxos comunicacionais que circulam em grupo de WhatsApp da equipe de produção. Por meio do dispositivo interacional construído, os jornalistas trocam referências a respeito de temas identificados e avaliados como pertinentes e relevantes para colocar no processo de circulação, numa tentativa de produzir fluxos que possam seguir adiante. Mesmo que a produção inicie 24 horas antes do programa ir ao ar, a partir de trocas constantes entre produtores e apresentadores que avaliam o que pode e merece ser tratado no programa, concebe-se que há processos comunicacionais reiterados, alimentados constantemente.

Por meio de práticas que incluem observação, identificação de dados e avaliação de temas discutidos no grupo do WhatsApp e nas redes (seja pessoal, social ou digital) podem ocorrer apropriações para integrar o programa. Segundo o jornalista Felipe Nogueira, os comentários nas redes sociais digitais podem ser utilizados como pauta. Para isso, são selecionadas informações e direcionadas aos apresentadores, os quais decidem se o tema vai ser problematizado ou não. Entretanto, antes da sugestão de pauta ser proposta, em alguns casos, há um processo de investigação pela equipe de reportagem.

Tais capturas realizadas pelos jornalistas num processo reiterado de curadoria, podem se tornar um momento fundamental para constituição de fluxos. Essas estações ou pontos nodais (BRAGA, 2017) funcionam como uma espécie de articulação para o encadeamento de novas ações interacionais, as quais terão a possibilidade de 
continuar a problematizar a temática, num processo dinâmico e criativo. Os sujeitos envolvidos nessa trama comunicacional se apropriam dos sentidos produzidos pelos jornalistas e os ressignificam, dando possibilidade de geração de novos sentidos e, assim, condições de avançar os fluxos comunicacionais por meio da geração de novos circuitos, sejam midiáticos ou não.

Os produtores e apresentadores utilizam de avaliações específicas para identificar fragmentos discursivos do que está em evidência nas timelines, seja em número de menções ou destaques dados pelos participantes das redes sociais digitais ou mesmo pelas mídias. Essas saliências são avaliadas, em alguns momentos, como fagulhas. Esses indícios devem se transformar em elementos capazes de desencadear interpretações pela ampliação da fagulha - um start - por meio de contextualizações dadas em formatos que constituem a engenharia do programa, como por exemplo uma entrevista, uma notícia, uma nota lida ou o acesso a um vídeo. As mensagens dos participantes que circulam nas redes sociais digitais e que dialogam com as perspectivas dos apresentadores dão condições para interpretações da economia discursiva, tecendo conversações em torno dos temas e lançando mão de juízos de valores próprios.

Entretanto, diante de processos de circulação amplos e difusos, a apreensão se dá por meio de fragmentos discursivos, já que o tecido social é tão amplo e complexo, que não permite a apropriação de sua totalidade. Os produtores e apresentadores têm noção dessa amplitude conversacional e dos múltiplos circuitos comunicacionais, então fazem escolhas: "hoje, a opinião chega, mas é impossível acompanhar opiniões de maneira mais apurada, pega-se uma coisa ou outra"7.

Concorda-se com Braga (2017, p. 47) quando postula que os retornos não são diretos, mas diferidos e difusos, pois trata-se de um "[...] circuito ampliado e não a volta imediata ao ponto de partida". Nessa perspectiva, os ângulos eleitos para abordagem ao longo do programa nascem de capturas dos pontos de vistas dos participantes, ou seja, são por meio de fluxos e contrafluxos comunicacionais que o programa se organiza.

Outro fluxo comunicacional utilizado para tentar estreitar o contato com os participantes 
é estruturado a partir da emissão de imagens do programa por meio de lives transmitidas do perfil no Facebook. As imagens constroem uma narrativa complementar à semiose radiofônica tradicional, pois ampliam a experiência de consumo e, ao mesmo tempo, dinamizam a possibilidade de constituição de outros circuitos.

De forma tentativa e tomando como desafio metodológico compreender a arquitetura interativa dinamizada pelo Timeline, elaborou-se um fluxograma para sintetizar esses fluxos comunicacionais e que foram identificados e descritos como estruturadores de circuitos interacionais. Como dito anteriormente, parte-se do pressuposto que de a sociedade está em vias de midiatização, pois concebe-se que essas processualidades estão em curso e ocorrem devido à ação dos sujeitos participantes, seja em ambientes midiáticos ou não.

Figura 1-Fluxos comunicacionais dinamizados pelo Timeline

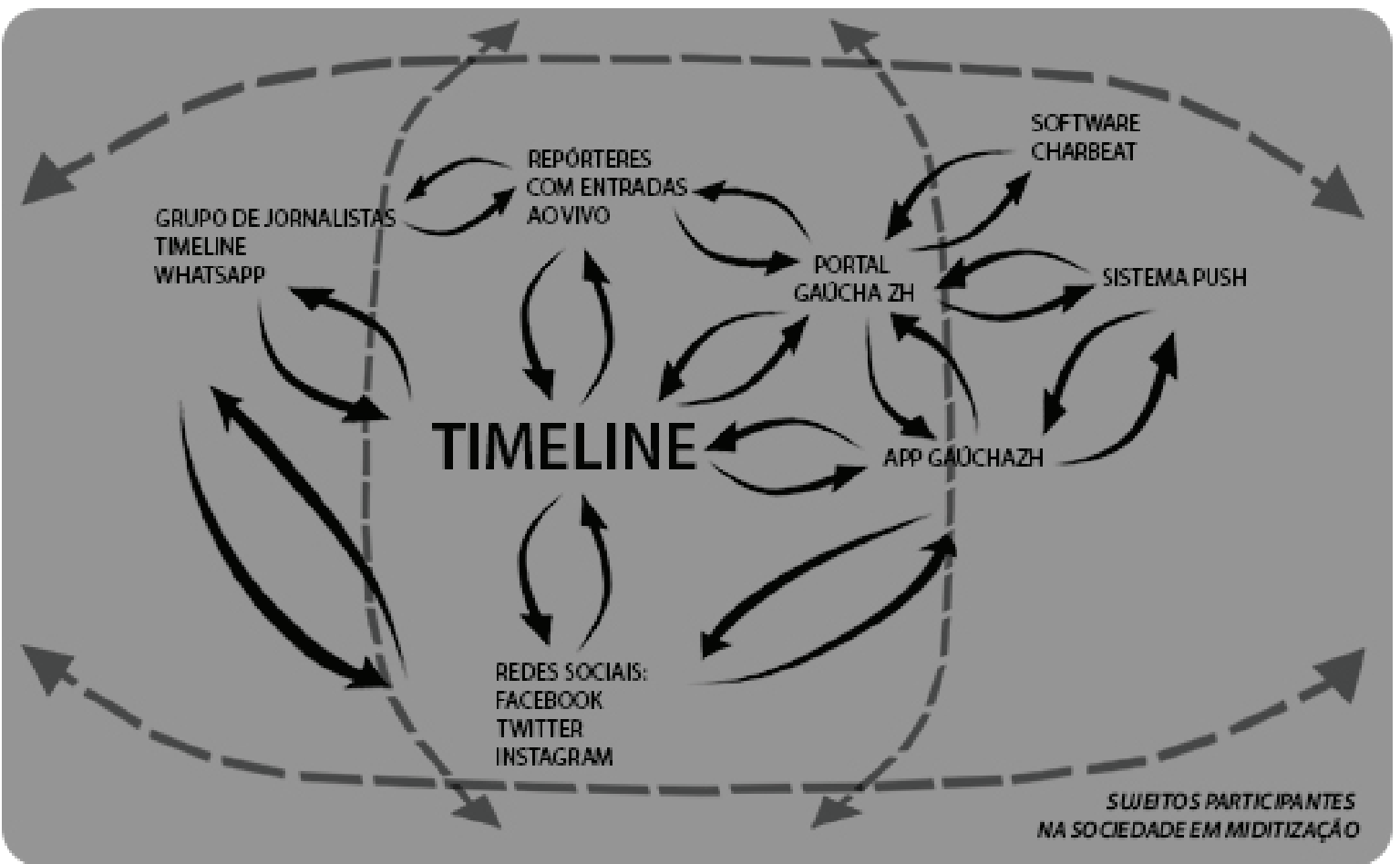

Fonte: Elaborado pelos autores (2019). 
A partir das estratégias metodológicas adotas na investigação, como forma de complementar às técnicas de pesquisa anteriormente aplicadas, analisou-se fragmentos discursivos (VERón, 2004, 2013) - postados na aba ${ }^{8}$ de avaliações do perfil do Timeline no Facebook -, que remetam a uma processualidade em curso, à transformação do próprio dispositivo radiofônico e à dinâmica interacional entre produção e reconhecimento. Optou-se por não identificar os sujeitos participantes que comentaram na página do Timeline e apenas transcrever suas falas, preservando suas identidades.

Compreende-se que a dinamicidade da arquitetura do dispositivo interacional vai além da escuta, pois denota operações em curso em função dos processos de circulação, que, como lembra Fausto Neto (2010, 2016), deixam marcas de sua existência para além de ser apenas um ponto de passagem entre produção e recepção. a) "Olha este programaé atual, com apresentadores inteligentes e fico orgulhoso de ser Gaúcho e o Timeline com certeza poderia ser um programa de Tv!!!”' (grifo nosso).

b) Muito bom e dinâmico. O mais interessante é que as informações vão surgindo em tempo real e, assistir o programa, certamente, traz um tom de vida real. Parabéns! ${ }^{10}$ (grifo nosso).

c) Eu escuto, ouço e vivo o time line todos os dias, adoro vocês dois e o geito que vocês analisam e discutem os assuntos diários. Obrigado por me informar de me transformar (sic) ${ }^{11}$.(grifo nosso).

Os sujeitos participantes desse ambiente midiático expressam suas opiniões nesse locus que permite a publicação de comentários. Salienta-se que há regras impostas pela própria rede social para a aba Avaliações, bem como normas do perfil do programa, visto que há uma moderação, em que alguns

8 Dados coletados em 27 de novembro de 2018, a partir dos resultados que retornam à pesquisa permitida pelo Facebook, o que compreende o período de três anos. Disponível em: <https://www.facebook.com/timelinegaucha/>. Acesso em: 27 de novembro de 2018.

9 Comentário postado em 27 de maio de 2016. Disponível em: <https://www.facebook.com/timelinegaucha/>. Acesso em: 27 nov. 18.

10 Comentário postado em 10 de junho de 2016. Disponível em: <https://www.facebook.com/timelinegaucha/>. Acesso em: 27 nov. 18.

11 Comentário postado em 13 de maio de 2016. Disponível em: <https://www.facebook.com/timelinegaucha/>. Acesso em: 27 nov. 18. 
comentários podem ser excluídos e mudados de ordem, por exemplo.

De modo geral, observa-se que os comentários destacam a dinamicidade do programa (comentário a: "atual”; comentário b: "dinâmico"; "tempo real"), o formato híbrido (comentário a: "poderia ser programa de TV") e como ele interfere e faz parte da vida dos sujeitos participantes (comentário a: "traz um tom de vida real"; comentário c: "vivo o time line"; "me transformar"). Ao mesmo tempo em que há gramáticas de produção específicas que denotam a reestruturação do dispositivo radiofônico, os participantes produzem marcas discursivas que apontam para essas mutações.

Nota-se que as marcas discursivas em reconhecimento indicam aspectos relativos à instantaneidade, temporalidade, atualidade, experiência, hibridização de formatos midiáticos, ou seja, o rádio hipermidiático, conforme aponta Lopez (2010). Esses fragmentos discursivos, como define Verón (2004, 2013) acerca da semiose social, evidenciam processualidades em curso em que atores sociais, mídias e instituições afetam-se mutuamente, transformando a sociedade. Tais indícios expressados pelos participantes por meio desse dispositivo interacional, demonstram, ainda, a afetação de lógicas midiáticas e não midiáticas que a sistemática de construção de fluxos coloca em marcha para fazer circular.

\section{Sobre circuitos em construção}

Como mencionado anteriormente, através da perspectiva da comunicação quando disciplina indiciária (BRAGA, 2007, p. 15), é preciso olhar para a singularidade de um objeto e pensá-lo como "gerador de conhecimentos mais amplos". Como lembra o autor, o paradigma indiciário implica na elaboração de proposições de ordem mais abrangente a partir dos dados singulares. Nesse sentido, serão feitas inferências específicas ao que foi observado em relação à construção de circuitos e de fluxos comunicacionais dinamizados pelo Timelime, bem como serão indicadas pistas que apontem para questões e reflexões mais gerais.

Como referem Sebeok e Umiker-Sebeok (2004) ao problematizar o método adotado por Charles Pierce e Sherlock Holmes, é a partir da observação dos pequenos fatos e das particularidades que podem ser feitas inferências mais amplas. Assim, compreende-se que a partir da análise da singularidade do Timeline possam ser indicadas pistas de mutações nos modos de fazer jornalismo e de complexidades que perpassam a construção de fluxos comunicacionais.

Recorda-se que a pesquisa desenvolvida teve como horizonte o desafio proposto por Verón 
(2004, 2013) de que não basta estudar as gramáticas de produção, já que estas estão vinculadas as gramáticas de reconhecimento em um processo de semiose infinita. Nesse contexto, para Fausto Neto $(2010,2016)$ e Braga $(2012,2017)$ é preciso estudar a circulação para compreender a sociedade em midiatização, na qual não predominam lógicas de um ou outro meio, nem mesmo modos de funcionamento de determinadas mídias. A profusão de fluxos comunicacionais possíveis de serem observados num contexto de circulação discursiva instiga inferências a respeito da reconfiguração das relações entre produção e recepção.

Em função da complexidade do processo de midiatização da sociedade, outra problemática vem à tona - a da manutenção do contato diante dos múltiplos fluxos comunicacionais que ocorrem de forma constante e difusa. Garantir não só contato dos participantes, mas sua preservação no mercado faz com que não apenas o espaço publicitário seja ampliado, mas também se utilize dos dados da curadoria e dos algoritmos para capturar futuros investidores.

Nesse sentido, o programa radiofônico Timeline opera estratégias para que os participantes possam consumir o produto e, por consequência, assinar os serviços oferecidos pelo portal GaúchazH. A publicidade é mencionada no decorrer do programa e segue posteriormente pelas redes sociais digitais e pelo portal, visto que ao visualizar alguma informação, são enunciadas possibilidades de assinatura para conteúdo exclusivo.

Os ouvintes não são acionados para integrar o dispositivo de enunciação apenas durante sua transmissão ao vivo - por meio de pedidos de participação (seja pelo telefone, WhatsApp, e-mail, perfil no Facebook ou portal) - mas em fluxos contínuos, já que cliques, curtidas, comentários e retuítes servem de indicadores para que o software Chartbeat produza métricas do que está sendo mais falado e que, portanto, decorrem da ação dos sujeitos participantes da sociedade em midiatização.

A narrativa construída pelo Timeline e distribuída em distintos suportes tenta manter no áudio o seu foco e explora a construção de fluxos a partir de conteúdos advindos de circuitos de múltiplas plataformas midiáticas ou não. As articulações entre o que circula no tecido social e o que poderá ser problematizado no espaço discursivo do programa radiofônico são ações estratégicas que ressignificam práticas midiáticas visando construir uma nova estação ou ponto nodal. A prática de mesclar características identitárias do rádio e do programa com as lógicas midiatizadas do ambiente digital sustenta os modos de organização específicos do dispositivo radiofônico, já que 
este, por sua vez, é afetado por lógicas crescentes de fluxos comunicacionais difusos.

No contexto da circulação, o dispositivo radiofônico estrutura-se em torno de operações que se ajustam conforme o redesenho de fluxos comunicacionais vivos, em dinamização por meio de narrativas complexificadas (LOPEZ, 2010). À luz de efeitos da midiatização da sociedade, o Timeline constrói circuitos comunicacionais ajustados às lógicas de uma economia discursiva projetada para funcionar em tramas complexificadas. São as práticas discursivas produzidas pelos sujeitos envolvidos em diferentes pontos nodais que nutrem e dão vida aos circuitos.

As bases do processo de apuração de informações dos jornalistas que produzem e apresentam o Timeline se estabelecem à luz de processos curadores, de filtragem ininterrupta, redesenhando a paisagem dos fluxos laborais. Nesse cenário, os jornalistas se caracterizam como multitarefa e já não mais produzem o programa sozinhos, pois contam com a cooperação e a conexão entre os sujeitos participantes. A partir de uma dinâmica de constituição de uma espécie de modelo de curadoria colaborativa, a narrativa construída e que expressa os acontecimentos não se fundamenta nos tradicionais valores-notícia outrora empregados, mas numa gama muito mais ampla de valores, crenças e interpretações que complexificam as rotinas produtivas e questionam o papel do gatekeeper, já que há gatewatchings, curadores de informações, entre outros sujeitos que entram em cena nas radiomorfoses. Os três apresentadores do Timeline não só enunciam notícias, mas as comentam, emitem interpretações sobre o que é dito e opinam, numa mescla de formatos em que fica difícil identificar os limites entre o informativo e o entretenimento. Ferraretto (2010) já mencionava as possibilidades estratégicas do dispositivo radiofônico, a exemplo de outras plataformas midiáticas, de responder aos participantes por meio do desenvolvimento de comentários com a interpretação e análise dos acontecimentos, proposição de mesas-redondas e entrevistas, buscando diferenciações com relação à concorrência.

Circuitos comunicacionais não são mais produzidos tendo como base apenas o que se considera notícia, novidade, notabilidade, proximidade, relevância, temporalidade, interesse público, entre outros parâmetros da mídia para avaliar o que é notícia. Ao analisar os fluxos comunicacionais dinamizados pelo Timeline e sua arquitetura interacional, nota-se que entram em cena subjetividades captadas a partir de sistemas curadores formulados pelo ambiente midiático. No caso observado, a lógica do algoritmo afeta os modos de fazer jornalismo, pois é preciso comentar o que está 
nos trending topics e o que está sendo falado nas redes sociais digitais por meio da emissão de opinião e comentário, geralmente com alguma dose de humor.

A lógica dos fluxos sempre adiante e da construção permanente dos circuitos organiza comunidades. A amplitude da participação dos sujeitos tem como consequência a (des) qualificação - seja na forma de comentário, curtida, retuíte, publicação, compartilhamento, etc. -, a identificação do que merece ser mencionado, redirecionado, reinterpretado, ampliado ou filtrado. Tais economias discursivas reconstroem o modus operandi jornalístico, reestrutura o dispositivo radiofônico e, muito mais, mantém viva a sociedade em vias de midiatização.

\section{Referências}

ALMEIDA, Ana Carolina.; MAGNONI, Antônio Francisco. Rádio e Internet: recursos proporcionados pela web ao radiojornalismo. In: CONGRESSO BRASILEIRO DE CIÊNCIAS DA COMUNICAÇÃO, 32., 2009, Curitiba.

Anais... Curitiba: Intercom, 2009.

BRAGA, José. Luiz. Circuitos de Comunicação. In: BRAGA, José Luiz; CALAZANS, Regina; RABELO, Leon et al. Matrizes interacionais: a comunicação constrói a sociedade. Campina Grande: EDUEPB, 2017.

BRAGA, José Luiz. Circuitos versus campos sociais. In: MATTOS, Maria Ângela, JANOTTI JUNIOR, Jeder, JACKS, Nilda., orgs. Mediação
\& midiatização [online]. Salvador: EDUFBA, 2012, pp. 29-52.

Comunicação, disciplina

indiciária. Matrizes, v. 1, n. 2, p. 73-88, abr. 2008. Disponível em: < www.matrizes. usp.br/ojs/index.php/matrizes/article/ download/46/28>. Acesso em: 6 mar. 2016.

DEL BIANCO, Nélia Rodrigues. Promessas de mudanças na programação e na linguagem das emissoras digitalizadas. In: MAGNONI, Antônio Francisco.; CARVALHO, Juliano Maurício de . O novo rádio: cenários da radiodifusão na era digital. São Paulo: Editora Senac, 2010. p. 91-112.

FAUSTO NETO, Antonio Da convergência/ divergência à interpenetração. In: MIÉGE, Bernard et al. Operações de midiatização: das máscaras da convergência às críticas ao tecnodeterminismo. 1. ed. Santa Maria: FACOS UFSM, 2016.

Mediação, midiatização: conceitos entre trajetórias, biografias e geografias. In: FERREIRA, Jairo et al. Entre o que se diz e o que se pensa: onde está a midiatização? Santa Maria: FACOS-UFSM, 2018. p. 63-99.

As bordas da circulação... Revista

ALCEU, v. 10, n. 20, p. 55-69, jan./jun. 2010. Disponível em: $<$ http://revistaalceu.com.pucrio.br/media/Alceu2o_Neto.pdf $>$. Acesso em: 12 dez. 2018.

FERNÁNDEZ, Jose Luis. Acedios a la radio. In: SCOLARI, Carlos. (Org). El fin de los médios masivos: el comienzo del debate. Buenos Aires: La Crujia, 2009.

FERRARETTO, Luiz Arthur. A. Rádio contemporâneo: o modelo de negócio e o poder de referência do meio sob tensão. 
Revista Eptic, v. 21, n. 2, p. 154-170-X, maio/ ago. 2019. Disponível em: <https://seer.ufs.br/ index.php/eptic/article/view/11508>. Acesso em:30 set. 2019.

Alterações no modelo comunicacional radiofônico: perspectivas de conteúdo em um cenário de convergência tecnológica e multiplicidade da oferta. In: CONGRESSO BRASILEIRO DE CIÊNCIAS DA COMUNICAÇÃO, 32., 2009, Curitiba. Anais... Curitiba: Intercom, 2009.

GARCÍA AVILÉS José Alberto.; SALAVERRÍA, Ramón.; MASIP, Pere Masip. Convergencia periodística em los medios de comunicación. Propuesta de definición conceptual y operativa. In: CONGRESO DE LA ASOCIACIÓN ESPAÑOLA DE INVESTIGADORES EM COMUNICACIÓN, 1., 2008, Santiago de Compostela, 2008. Anais... Santiago de Compostela: Asociación Española de Investigadores em Comunicación, 2008.

GINZBURG, Carlo. Sinais: raízes de um paradigma indiciário. In: Mitos, emblemas, sinais: morfologia e história. São Paulo, Companhia da Letras, 1989.

\section{GIL. Antônio Carlos. Métodos e técnicas de} pesquisa social. 6.ed. São Paulo: Atlas, 2008. GOMES. Pedro Gilberto. Dos meios à midiatização: um conceito em evolução. São Leopoldo, RS: Editora Unisinos, 2017.

JENKINS, Henry. Cultura da convergência. São Paulo: Aleph, 2008.

KISCHINHEVSKY, Marcelo. Rádio e mídias sociais: mediações e interações radiofônicas em plataformas digitais de comunicação. 1. ed. Rio de Janeiro: Mauad X, 2016.
LOPEZ, Débora Cristina. Radiojornalismo hipermidiático: tendências e perspectivas do jornalismo de rádio all news brasileiro em um contexto de convergência tecnológica. Covilhã: LabCom, 2010.

PRATA, Nair. Webradio: novos gêneros, novas formas de interação. 2008. $395 \mathrm{f}$. Tese (Doutorado em Linguística Aplicada)Universidade Federal de Minas Gerais, Belo Horizonte, 2008. Disponível em: <https:// repositorio.ufmg.br/bitstream/1843/>. Acesso em: 30 set. 2019.

SEBEOK, Thomas. A.; UMIKER-SEBEOK, Jean. Você conhece o meu método: uma justaposição de Charles S. Peirce e Sherlock Holmes. In: ECO, Umberto; SEBEOK, Thomas, A. (Org.). $O$ signo de três. São Paulo, Perspectiva, 2004.

VERÓN, Eliseo. Esquema para el análisis de la mediatización. Revista Diálogos de La Comunicación, n. 48, 1997.

Fragmentos de um tecido. São

Leopoldo: Editora Unisinos, 2004.

La Semiosis Social 2: Ideas, momentos, interpretantes. 1. ed. Ciudad Autónoma de Buenos Aires: Paidós, 2013. 


\section{Informações sobre 0 artigo}

Resultado de projeto de pesquisa, de dissertação, tese: 0 artigo resulta de pesquisa conjunta realizada pelos docentes, como parte integrante das pesquisas individuais: "A circulação discursiva no contexto de midiatização da sociedade" (em desenvolvimento desde 2018 e que possui coordenação da professora doutora Viviane Borelli. A pesquisa conta com auxílio - para coleta de dados-de alunos de graduação que possuem bolsas de iniciação científica-Pibic-Cnpq, Probic-Fapergs e Fipe Sênior-CCSH UFSM) e "Rotinas produtivas jornalísticas e as características dos conteúdos radiofônicos disponibilizados nos aplicativos móveis de celular da Rádio Gaúcha, de Porto Alegre e CBN, de São Paulo" (coordenação do professor Maicon Elias Kroth e que é desenvolvida desde 2017, no âmbito do Departamento de Ciências da Comunicação da UFSM).

Fontes de financiamento: não se aplica.

Considerações éticas: não se aplica.

Declaração de conflito de interesses: não se aplica.

Apresentação anterior: uma versão preliminar do artigo foi apresentado ao Grupo de Trabalho de Recepção, Circulação e Usos Sociais das Mídias do XXVIII Encontro Anual da Compós, Pontifícia Universidade Católica do Rio Grande do Sul, Porto Alegre-RS, 11 a 14 de junho de 2018.

Agradecimentos/Contribuições adicionais: Agradecimento ao aluno de iniciação científica, Pablo Furlanetto, bolsista Probic da Fapergs do Rio Grande do Sul, de 2017 a 2018, por ajudar na diagramação da figura 1. 


\section{Circulation and circuits under construction: the radiodynamic}

\begin{abstract}
This work examine show communication flows are structured, powered by the action of the participant subjects in a mediatized environment, captured by the radio show Timeline, on Radio Gaúcha, Porto Alegre, Brazil. By conducting interviews, hearings and the observation of the program's journalists' personal profiles on Facebook, it was possible to describe interactional circuits and also problematize how the discursive circulation reconfigures the radio device. The analysis of the communication flows denotes the construction of a systematized architecture of complex circuits in which the circulation emerges and restructures practices not only on radio, but also of the society on mediatization.
\end{abstract}

\section{Keywords}

Circulation. Circuits. Radio. Mediatization.

\section{Circulación y construcción de circuitos: la dinámica de la radio}

\section{Resumen}

Analizamos la forma en que los flujos de comunicación son dinamizados por la acción de los sujetos que participan em el proceso de mediatización de la sociedade y que son capturados por el programa Timeline de la radio Gaúcha en Porto Alegre, RS. Desde la realización de entrevistas, audiciones y observación de los perfiles de los periodistas y el programa em Facebook, describimos circuitos interactivos, detallamos el funcionamiento y mostramos la reconfiguración del dispositivo radiofónico. El análisis de los flujos de comunicación denota la constitución de una arquitectura de circuitos complejos en los que la circulación emerge y reestructura las prácticas no solo del radio, sino también de la sociedad en mediatización.

\section{Palabras clave}

Circulación. Circuitos. Radio. Mediatización.

\section{Viviane Borelli}

Doutora em Comunicação pelo Programa de PósGraduação em Ciências da Comunicação da Universidade do Vale do Rio dos Sinos. Jornalista e Mestre pela Universidade Federal de Santa Maria. Professora Associada do Departamento de Ciências da Comunicação e docente do Programa de PósGraduação em Comunicação Universidade Federal de Santa Maria. Universidade Federal de Santa Maria, Santa Maria, Rio Grande do Sul, Brasil. E-mail: viviborelli10@gmail.com ORCID: https://orcid.org/0000-0003-0643-2173

\section{Maicon Elias Kroth}

Doutor em Comunicação pelo Programa de PósGraduação em Ciências da Comunicação da Universidade do Vale do Rio dos Sinos. Jornalista pela Universidade de Santa Cruz do Sul e Mestre pela Pontifícia Universidade Católica do Rio Grande do Sul. Professor Adjunto do Departamento de Ciências da Comunicação da Universidade Federal de Santa Maria. Universidade Federal de Santa Maria, Santa Maria, Rio Grande do Sul, Brasil.

\author{
Contribuição dos autores \\ Concepção e desenho do estudo: \\ Viviane Borelli; Maicon Kroth \\ Aquisição, análise ou interpretação dos dados: \\ Viviane Borelli; Maicon Kroth \\ Redação do manuscrito: Viviane Borelli; Maicon Kroth \\ Revisão crítica do conteúdo intelectual: \\ Viviane Borelli; Maicon Kroth
}

